\title{
COMPORTAMENTO DA ACIDEZ TOTAL E AMIDO NA PRODUÇÃO DA FARINHA DE MANDIOCA DO GRUPO SECA
}

\section{TOTAL ACIDITY AND STARCH BEHAVIOUR IN THE CASSAVA FLOUR PRODUCTION OF DRY GROUP}

\author{
Renan Campos Chisté ${ }^{1}$; Kelly de Oliveira Cohen ${ }^{2}$ \\ ${ }^{1}$ Federal University of Pará - UFPA - Belém-PA - Brasil renanchiste@gmail.com \\ ${ }^{2}$ Embrapa Amazônia Oriental - Belém-PA - Brasil ko_cohen@yahoo.com.br
}

\begin{abstract}
Resumo
A farinha de mandioca do grupo seca apresenta dificuldade na adequação perante aos parâmetros exigidos pela legislação vigente, principalmente acidez total e amido, devido às diferentes condições de processamento da mandioca. Sendo assim, o objetivo do presente trabalho, é apresentar o estudo do comportamento da acidez total e do amido no decorrer do processamento da mandioca, com e sem interrupção no processo, para obtenção de farinha. Os resultados mostram que a interrupção no processo de fabricação da farinha de mandioca aumentam o teor de acidez total e diminuem o teor de amido no produto final.
\end{abstract}

Palavras-chave: acidez; amido; processamento; Manihot esculenta.

\section{Introdução}

A mandioca (Manihot esculenta Crantz) desempenha um importante papel na dieta alimentar dos brasileiros, por seu alto teor energético. O Brasil figura como um dos maiores produtores dessa cultura e também como grande consumidor, apresentando em 1999 um consumo de raízes per capita de 42,9Kg/hab/ano, enquanto o consumo per capita mundial foi de apenas 16,4Kg/hab/ano (FAO, 2003).

A maioria da produção brasileira de mandioca é destinada à produção de farinha de mandioca. Ao contrário da produção de fécula, da mandioca de mesa e de raspas ou pellets, a farinha de mandioca não conta com mercados de exportação significativos. O Brasil é o único país da América Latina que consome farinha em quantidades expressivas (VILPOUX, 2003).

De acordo com o IBGE, PAM/LSPA (2005) estima-se que a média da produção brasileira de mandioca em 2003/04 foi de 22.871 ton., sendo os principais produtores: o estado do Pará com 4.457 ton., Bahia 4.027 ton., Paraná 2.656 ton., Rio Grande do Sul 1.275 ton., e Maranhão 1.257 
ton.

O estado do Pará, na condição de maior produtor brasileiro de mandioca, participa com 15\% da produção nacional. A produção de farinha de mesa, a principal forma de aproveitamento das raízes, é uma atividade de importância social porque um grande contingente da população rural participa desta produção, além de representar uma contribuição econômica significativa para os municípios paraenses (FONTES et al., 1999).

A planta de mandioca apresenta ciclo de desenvolvimento composto por cinco fases fisiológicas principais, sendo quatro ativas e uma de repouso vegetativo. A primeira fase é chamada de brotação da maniva com formação do sistema radicular; na segunda fase continua sendo formado o sistema radicular, constituído por raízes fibrosas; na terceira fase ocorre o desenvolvimento da parte aérea da planta e, simultaneamente, o espessamento de algumas raízes fibrosas, pelo acúmulo de amido; a quarta fase é o espessamento das raízes de reserva, nessa fase já não há mais crescimento das raízes em comprimento, mas em diâmetro, pela deposição do amido. A quinta fase é a de repouso vegatativo, e é durante essa fase que a planta de mandioca armazena o máximo de reserva de amido nas raízes (TERNES, 2002).

Chisté (2006) relata que após a trituração da mandioca, no processamento da farinha, parte deste material é lavado para a remoção do amido, que também é comercializado. O material lavado retorna ao processo de fabricação da farinha. Tal procedimento influencia no teor total de amido da farinha, resultando em valores abaixo do limite mínimo permitido pela legislação vigente. Como o principal constituinte da farinha de mandioca é o amido, quanto maior seu teor, melhor a qualidade do produto.

A acidez é um parâmetro de qualidade importante no que se refere à farinha de mesa, influenciando na percepção das características sensoriais do produto. Segundo a Portaria $\mathrm{n}^{0} 554$, de 30 de agosto de 1995 do Ministério da Agricultura (BRASIL, 1995), o limite máximo permitido é de 3 meq NaOH/100g para a farinha de mandioca. Chisté (2006) observou que no processamento da mandioca para a produção de farinha seca, a acidez apresentou aumento progressivo desde a mandioca descascada até o produto final devido a não-continuidade do processamento e às más condições das casas de farinha, ou seja, após a trituração da massa, ou após a prensagem da mesma, a torração da farinha muitas vezes ocorre no dia posterior ao início do processamento.

Sendo o amido o principal constituinte da farinha de mandioca, o presente trabalho teve por objetivo analisar seu comportamento durante o processamento da mandioca, assim como o comportamento da acidez total como demonstrativo importante na qualidade final do produto. 


\section{Material e Métodos}

Foram realizados dois processamentos da mandioca para produção de farinha do grupo seca em escala laboratorial, conduzidos da seguinte forma: uma quantidade de massa da raiz, após trituração, foi dividida em duas partes iguais: uma parte para processamento da farinha no mesmo dia da obtenção da matéria-prima (processamento A), e a outra parte para término do processamento 24 horas (em temperatura ambiente) após a trituração da raiz (processamento B). O objetivo foi acompanhar o aumento da acidez total durante o processo, assim como o comportamento do teor de amido em decorrência da fermentação da massa em repouso, assim como o realizado comumente em casas de farinha no interior do estado do Pará. Os procedimentos diferenciados têm por finalidade esclarecer o comportamento dos principais constituintes do produto final, a farinha de mandioca, como consequencia das modificações de seu processamento. Os experimentos foram realizados no Laboratório de Agroindústria da Embrapa Amazônia Oriental, em Belém-PA.

Para o acompanhamento da acidez total e amido, durante as etapas de processamento da farinha foi utilizada como matéria-prima, raízes de mandioca do cultivar Bem-te-vi (17 meses) cedidas pelo Banco de Germoplasma da Embrapa Amazônia Oriental, de acordo com a disponibilidade do cultivar.

Foram selecionados os seguintes pontos de coleta para análise: mandioca descascada, mandioca triturada, mandioca prensada e o produto farinha de mandioca. O processamento seguiu o fluxograma descrito na Figura 1.

Figura 1 - Etapas de processamento da mandioca para obtenção da farinha de mandioca do grupo seca.

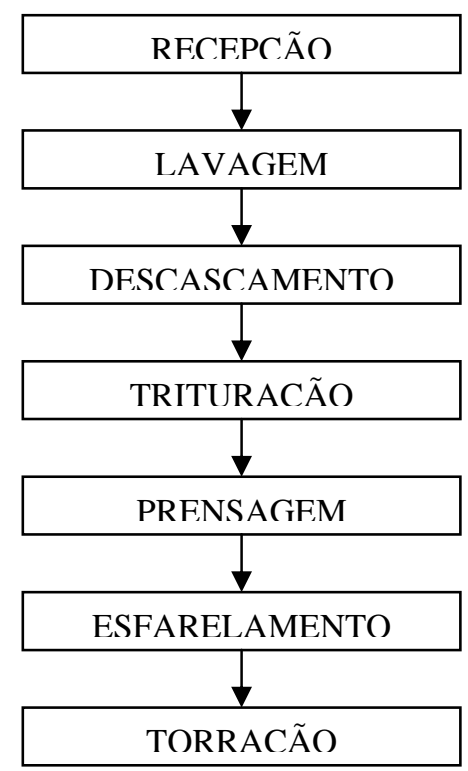




\subsection{Análises físico-químicas}

As análises foram realizadas no Laboratório de Agroindústria, da Embrapa Amazônia Oriental, em Belém-PA. São elas: teor de umidade - técnica de dessecação por aquecimento direto em estufa a $105^{\circ} \mathrm{C}$; teor de cinzas - incineração em forno mufla a $560^{\circ} \mathrm{C}$; teor de lipídios - extração de Soxhlet; teor de proteínas - técnica de digestão micro Kjeldahl; acidez total titulável determinada por titulação potenciométrica; sendo estas análises realizadas segundo as normas da AOAC (1997). A determinação do teor de amido foi realizada pelo método de hidrólise ácida em microondas, conforme a metodologia descrita por Cereda et al. (2004) e a atividade de água determinada em medidor de atividade de água portátil, modelo Pawkit, marca Decagon. Todas as análises foram realizadas em triplicata.

\section{Resultados e Discussão}

Na Tabela 1, são apresentados as médias dos resultados das análises de acidez total e amido durante as etapas de processamento da mandioca para a produção de farinha: sem interrupção (A) e a continuação do processo após interrupção de 24 horas (B).

Tabela 1 - resultados das análises de acidez total e amido nos diferentes processamentos.

\begin{tabular}{|c|c|c|c|}
\hline Processamento & Etapas & $\begin{array}{c}\text { Acidez total } \\
\text { (meq NaOH/100g) }\end{array}$ & $\begin{array}{c}\text { Amido } \\
(\%)\end{array}$ \\
\hline \multirow{3}{*}{ (A) } & Raiz descascada & ${ }^{\mathrm{C}} 0,94 \pm 0,03$ & $\mathrm{C}_{31,00 \pm 0,12}$ \\
\hline & Raiz triturada & ${ }^{\mathrm{C}} 0,98 \pm 0,01$ & $\mathrm{D}_{29,58 \pm 0,19}$ \\
\hline & Massa prensada & ${ }^{\mathrm{D}} 0,77 \pm 0,02$ & ${ }^{A_{37,26}} \pm 0,17$ \\
\hline \multirow{2}{*}{ (B) } & Raiz triturada após 24 horas de repouso & $\mathrm{A}_{1,29} \pm 0,09$ & ${ }^{\mathrm{E}} 28,57 \pm 0,27$ \\
\hline & Massa prensada & ${ }^{\mathrm{B}} 1,15 \pm 0,02$ & ${ }^{\mathrm{B}} 35,29 \pm 0,16$ \\
\hline
\end{tabular}

De acordo com os resultados apresentados na Tabela 1, para o processamento A, o teor de acidez total da raiz descascada não se difere significativamente da triturada, uma vez que o processo de trituração ocorre em seguida ao descascamento. No entanto, após a prensagem da massa triturada, nota-se redução na acidez total, pois parte da acidez é arrastada juntamente com o líquido extraído pela prensagem, a manipueira. Quanto ao teor de amido, o valor inicial da raiz de mandioca é de 31\%, após a trituração parte do amido é perdido em decorrência do processamento, e na prensagem da massa triturada, com a retirada do líquido e retenção da massa, é observado 
aumento no teor de amido, provavelmente em decorrência da concentração da massa prensada provocada pela retirada da manipueira.

Para o processamento $\mathrm{B}$, a raiz triturada que continha 0,98 meq $\mathrm{NaOH} / 100 \mathrm{~g}$ de acidez total, após 24 horas de repouso em temperatura ambiente, teve seu teor elevado para 1,29 em decorrência da fermentação da massa triturada, e como consequência houve diminuição no teor de amido da amostra de 29,58 para 28,57\%. Após a prensagem da massa triturada, o comportamento do teor de acidez total e amido apresenta-se semelhante ao processamento A, isto é, a acidez total teve seu valor reduzido para 1,15 meq NaOH/100g devido ao arraste dos ácidos orgânicos pela extração da manipueira, enquanto o teor de amido apresenta aumento para 35,29\% em função da concentração da massa prensada. Nota-se que o teor de amido na massa prensada sem fermentação é maior e difere-se significativamente da massa prensada após 24 horas de repouso da raiz triturada (processamento B).

Na Figura 2 encontram-se representados graficamente os resultados dos teores de acidez e de amido durante as etapas de processamento da farinha de mandioca do grupo seca da maneira como é comumente realizada na Casa de Farinha.

Figura 2 - Teores de acidez e de amido das etapas de processamento da farinha de mandioca do grupo seca elaborada em condições de fabricação comumente empregadas em Casas de Farinha (com interrupção).

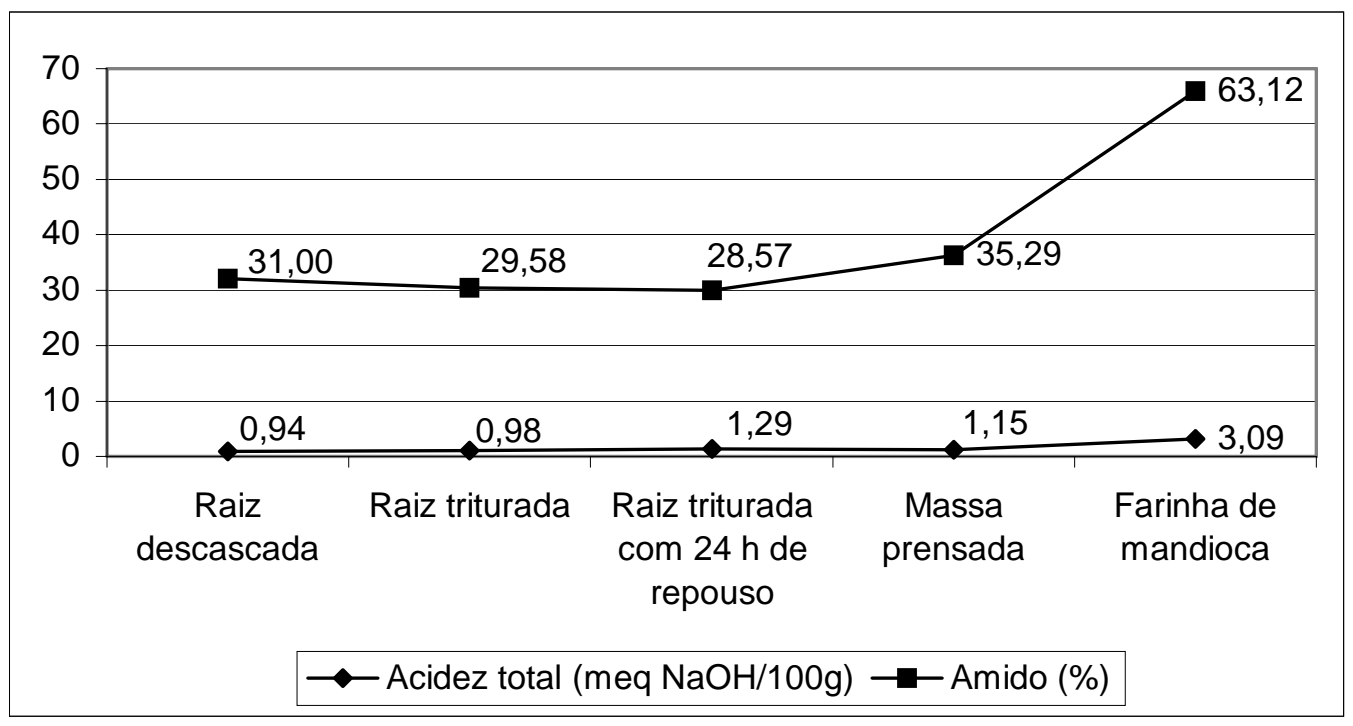

Na Figura 3 estão os resultados gráficos dos teores de acidez e de amido das etapas de processamento da farinha processada sem interrupções. 
Figura 3. Teores de acidez e de amido durante as etapas de processamento da farinha de mandioca do grupo seca elaborada sem interrupções.

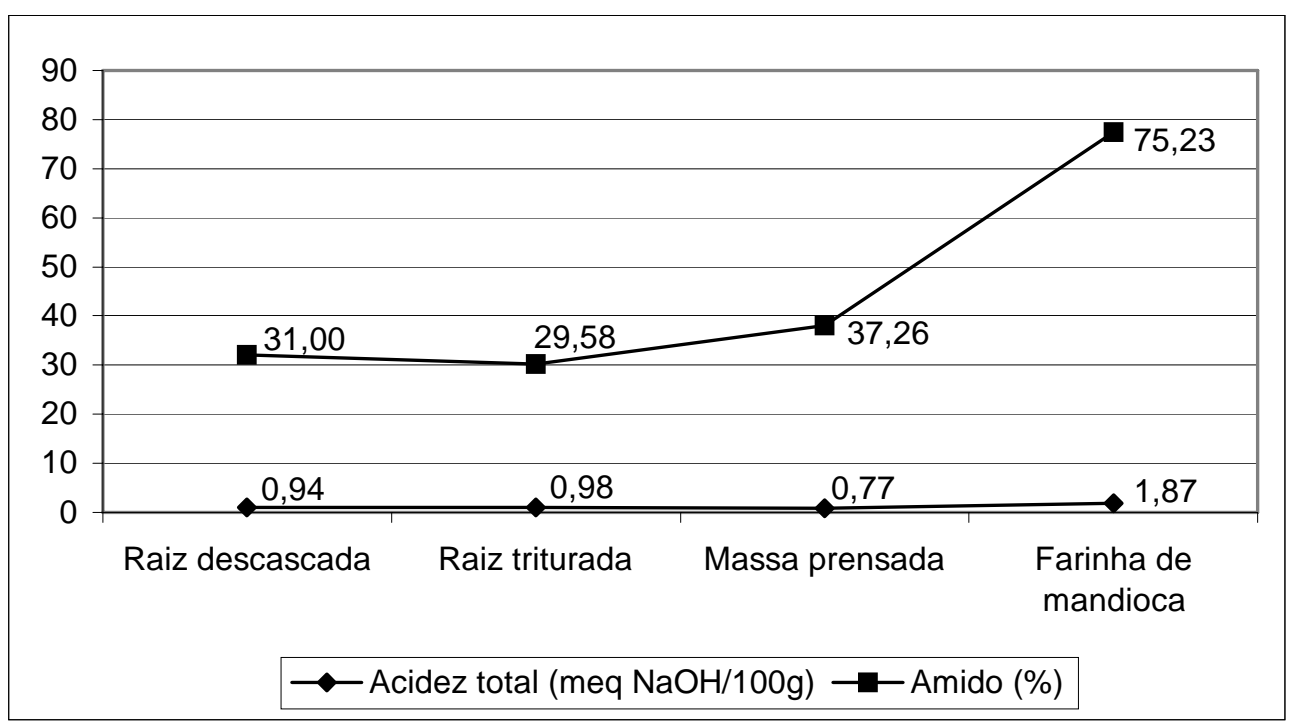

Na tabela 2, temos os resultados médios da caracterização físico-química das farinhas de mandioca do grupo seca produzidas sem interrupção no processamento (A) e com interrupção de 24 horas (B).

Tabela 2 - Características físico-químicas da farinha de mandioca obtida a partir dos diferentes processos.

\begin{tabular}{|c|c|c|c|c|c|c|c|}
\hline $\begin{array}{c}\text { Tipo de } \\
\text { Processo }\end{array}$ & $\begin{array}{c}\text { Umidade } \\
\text { (\%) }\end{array}$ & $\begin{array}{c}\text { Atividade } \\
\text { de água } \\
\text { (Aw) }\end{array}$ & $\begin{array}{c}\text { Cinzas } \\
(\%)\end{array}$ & $\begin{array}{c}\text { Acidez } \\
\text { total titulável } \\
\text { (meq } \\
\text { NaOH/100g) }\end{array}$ & $\begin{array}{c}\text { Proteínas } \\
\text { (\%) }\end{array}$ & $\begin{array}{l}\text { Lipídios } \\
\text { (\%) }\end{array}$ & $\begin{array}{c}\text { Amido } \\
(\%)\end{array}$ \\
\hline A & $\begin{array}{r}{ }^{\mathrm{B}} 4,56 \\
\pm 0,19\end{array}$ & ${ }^{\mathrm{B}} 0,29 \pm 0,01$ & $\begin{array}{r}{ }^{\mathrm{B}} 0,74 \\
\pm 0,02\end{array}$ & ${ }^{\mathrm{B}} 1,87 \pm 0,02$ & ${ }^{A} 1,07 \pm 0,11$ & ${ }^{\mathrm{A}} 0,73 \pm 0,18$ & ${ }^{A} 75,23 \pm 0,61$ \\
\hline B & $\begin{array}{l}{ }^{A} 5,60 \\
\pm 0,21\end{array}$ & ${ }^{\mathrm{A}} 0,39 \pm 0,02$ & $\begin{array}{l}{ }^{\mathrm{A}} 0,77 \\
\pm 0,02 \\
\end{array}$ & ${ }^{\mathrm{A}} 3,09 \pm 0,01$ & ${ }^{\mathrm{A}} 1,22 \pm 0,15$ & ${ }^{\mathrm{A}} 1,00 \pm 0,08$ & ${ }^{\mathrm{B}} 63,12 \pm 0,50$ \\
\hline
\end{tabular}

Médias com letras iguais, em uma mesma coluna, não diferem significativamente entre si (Teste de Tukey a 5\% de significância).

Com relação à umidade e cinzas, em ambos os processos, as amostras de farinha encontraram-se dentro dos padrões exigidos pela Portaria n ${ }^{0} 554$ de 30.08.1995 do Ministério da Agricultura, Pecuária e Abastecimento - MAPA (BRASIL, 1995), que é no máximo 13\% e 1,5\%, respectivamente.

Na farinha de mandioca processada sem interrupções (Figura 3), a acidez do produto final é de 1,87 meq NaOH/100g, abaixo do máximo permitido pela legislação que é de 3 meq NaOH/100g. Fato este que não ocorre quando a massa triturada é deixada em repouso, como se procede, normalmente, em Casas de Farinha, cujo produto final obteve 3,09 meq NaOH/100g (Figura 2). 
É importante observar que, mesmo tentando simular o que ocorre nas Casas de Farinha, em laboratório as condições são mais facilmente controladas, uma vez que nas Casas onde se processam a farinha, a massa triturada fica armazenada em grandes quantidades, sem proteção e à temperatura ambiente.

A farinha submetida ao processo de descanso da massa triturada (24 horas) obteve 63,12\% de amido (Figura 2), enquanto que a farinha conduzida de forma correta, sem interrupções no processamento, obteve percentual de 75,23\% (Figura 3). Tal fato indica que a interrupção do processamento da farinha reduz o teor de amido do produto, baixando o padrão de qualidade para abaixo do limite estabelecido em legislação, que é de 75\%.

De acordo com a Portaria nº 554 de 30.08.1995 do MAPA, não há referências com relação aos valores de atividade de água e aos teores de lipídios e proteínas da farinha de mandioca. Entretanto, neste estudo, foram realizadas tais determinações como complemento de informações referentes aos constituintes da farinha.

Considera-se a atividade de água igual a 0,60 como sendo o limite mínimo capaz de permitir o desenvolvimento de microrganismos, daí o fato de os alimentos desidratados, como a farinha de mandioca, serem considerados microbiologicamente estáveis. Neste trabalho, as amostras em estudo apresentaram atividade de água na faixa de 0,29 (processamento A) a 0,39 (processamento B).

A farinha de mandioca é um produto que apresenta baixos teores de lipídios e de proteínas. Neste estudo, as amostras apresentam teores de proteínas de 1,07 e 1,22 \% e de lipídios 0,73\% e $1,00 \%$, para os processos A e B, respectivamente, os quais não se diferem significativamente com a alteração do processamento.

\section{Conclusão}

A interrupção do processo de fabricação da farinha de mandioca, ou seja, procedendo o repouso da massa triturada e/ou prensada e processamento no dia seguinte, proporciona aumento da acidez total e redução do teor de amido no produto final, desclassificando-o quanto ao padrão estabelecido pela legislação, haja vista que, o processo conduzido de maneira adequada (sem interrupções) proporciona a obtenção de farinha de mandioca com os teores de acidez total e amido dentro dos padrões exigidos pela legislação vigente, podendo então ser comercializado como um produto de qualidade assegurada. 


\begin{abstract}
The cassava flour of dry group shows difficulty in the adaptation before the parameters demanded by the effective legislation, mainly total acidity and starch, due to the different processing cassava conditions. So, the aim of this work is study the total acidity and starch behavior during the cassava processing, with and without interruption in the process, to get flour. The results show the interruption in the process of cassava flour production increased the total acidity value and it reduced the starch value from final product.
\end{abstract}

Key-words: acidity; starch; processing; Manihot esculenta.

\title{
Referências
}

AOAC. Official methods of analysis of the Association of Official Analytical Chemists: edited Ig W. Horwitz $16^{\mathrm{a}}$ ed. Washington, 850p. v.2. 1997.

BRASIL. Portaria no 554 de 30 de agosto de 1995. Diário Oficial. Brasília, Secretaria da Agricultura, do Abastecimento e reforma Agrária. 1 Set., Seção 1.

CEREDA, M.P.; DAIUTO, E.R.; VILPOUX, O. Metodologia de Determinação de Amido por Digestão Ácida em Microondas. Revista ABAM, p.29, 2004.

CHISTÉ, R.C.; Estudo das propriedades físico-químicas e microbiológicas na produção da farinha de mandioca dos grupos seca e d'água, subgrupo fina, tipo 1. (TCC - Trabalho de conclusão de curso). Universidade do Estado do Pará, CCNT, Belém-PA, 2006.

FAO. Statistical datas: http://apps.fao.org/cgi-bin/nph-db.pl. 24/abr/2003.

FONTES, Enéas de A..; MENEZES, Adélia de N.S. de; CARDOSO, Eloísa M.R.; NASCIMENTO, Rosival P. do; FABRICAÇÃO DE FARINHA DE MANDIOCA; Belém-PA: SENAR, 1999.

IBGE. Brasil: Mandioca - produção, área colhida e rendimento médio - 1990 a 2004. IBGE - Produção Agrícola Municipal (PAM - 1990 a 2003) e Levantamento Sistemático da Produção Agrícola (LSPA - maio/2005).

TERNES, M. Fisiologia da planta. In: CEREDA, M. P. (coord.). Agricultura: tuberoses amiláceas latino-americanas. Sâo Paulo: Fundação Cargill, 540p. (Série: culturas de tuberosas amiláceas latino-americanas, 2), 2002.

VILPOUX, Olivier. Produção de Farinha d’água no Maranhão. In Cd-rom. Série: Cultura de tuberosas amiláceas latino-americanas. Vol.3 Cap.21. Cultura de tuberosas amiláceas latino-americanas. Fundação Cargill. 2003.

\section{Inserir aqui dados completos de todos os autores:}

Nome completo: Renan Campos Chisté.

Filiação institucional: Universidade Federal do Pará - UFPA.

Departamento: Departamento de Engenharia Química e Alimentos - DEQAL.

Função ou cargo ocupado: Mestrando em Ciência e Tecnologia de Alimentos.

Endereço completo para correspondência (bairro, cidade, estado, país e CEP): Trav. WE 23, n61,

Cidade Nova 4, bairro Coqueiro, Ananindeua-PA, Brasil. CEP: 67133-060.

Telefones para contato: (91)32634058.

e-mail: renanchiste@gmail.com 
Nome completo: Kelly de Oliveira Cohen.

Filiação institucional: Embrapa Amazônia Oriental.

Departamento: Laboratório de Agroindústria.

Função ou cargo ocupado: Pesquisador III.

Endereço completo para correspondência (bairro, cidade, estado, país e CEP): Trav. Dr. Enéas

Pinheiro s/n, Caixa Postal 48, Belém-PA, Brasil. CEP 66095-100.

Telefones para contato: (91) 32041037.

e-mail: ko_cohen@yahoo.com.br 